\title{
Long term outcome of anastomotic leakage in patients undergoing low anterior resection for rectal cancer
}

\author{
Alice Artus $^{1 \dagger}$, Nicolas Tabchouri ${ }^{1 \dagger}$, Othman Iskander ${ }^{1}$, Nicolas Michot ${ }^{1}$, Olivier Muller ${ }^{1}$, Urs Giger-Pabst ${ }^{2}$, \\ Pascal Bourlier ${ }^{1}$, Céline Bourbao-Tournois ${ }^{1}$, Aurore Kraemer-Bucur ${ }^{1}$, Thierry Lecomte ${ }^{3}$, Ephrem Salamé ${ }^{1}$ and \\ Mehdi Ouaissi ${ }^{1 *}$ (D)
}

\begin{abstract}
Background: The influence of anastomotic leakage (AL) on local recurrence rates and survival in rectal cancer remains controversial. The aim of this study was to analyze the effect of asymptomatic anastomotic leakage (AAL) and symptomatic anastomotic leakage (SAL) on short- and long-term outcome after curative rectal cancer resection.

Methods: All patients who underwent surgical resection of non-metastatic rectal cancer with curative intent from January 2005 to December 2017 were retrospectively analyzed. Short-term morbidity, long-term functional and oncological outcomes were compared between patients with SAL, AAL and without AL (WAL).

Results: Overall, 200 patients were included and AL was observed in 39 (19.5\%) patients (10 AAL and 29 SAL) with a median follow-up of 38.5 months. Rectal cancer location and preoperative neoadjuvant treatment was similar between the three groups. Postoperative 30-day mortality rate was nil. The permanent stoma rate was higher in patients with SAL or AAL compared to WAL patients ( 44.8 and $30 \%$ vs $9.3 \%, p<0.001)$. The mean wexner continence grading scale was significantly different between AAL $(11,4 \pm 3,8)$, SAL $(10,3 \pm 0,6)$ and WAL $(6,4 \pm 4,7)$ groups $(p=0.049)$. The 3 and 5 year overall and disease-free survival rates were similar between the 3 groups ( $86.6 \% / 84 \%$ vs $100 \% / 100 \%$ vs $76 \% / 70$ and $82.9 \% / 77 \%$ vs $100 \% / 100 \%$ vs $94.7 \% / 88.3 \%$ for patients with SAL, AAL, and WAL, $p=0.480$ and $p=0.527$ ).
\end{abstract}

Conclusion: The permanent stoma rate was significant higher in patients with SAL or AAL compared to WAL patients. AL did not impair long-term oncological outcome.

Keywords: Rectal cancer surgery, Anastomotic leakage, Local recurrence, Low anterior resection score, Functional outcome, Long-term outcome

\section{Background}

The management of rectal cancer has substantially improved and standardized in the past twenty years. Preoperative chemoradiotherapy (CRT) followed by total mesorectal excision (TME) is now the gold standard for

\footnotetext{
* Correspondence: m.ouaissi@chu-tours.fr

${ }^{\dagger}$ Alice Artus and Nicolas Tabchouri contributed equally to this work. 'Department of Digestive, Oncological, Endocrine, Hepato-Biliary, Pancreatic and Liver Transplant Surgery, Trousseau Hospital, Chambray les Tours, Avenue de la République, Chambray les Tours, France

Full list of author information is available at the end of the article
}

locally advanced rectal carcinoma [1-4]. Indeed, TME has led to decreased local recurrence rates and increased cancer-specific survival rates [5]. More recently, technical advances include also an intersphincteric approach for resection $[6,7]$ which, combined with a neoadjuvant treatment [4], aims to reduce the permanent stoma rate in patients undergoing low rectal cancer surgery. Despite numerous improvements, anastomotic leakage (AL) remains the most dreaded complication following rectal resection [8-10]. Its occurrence is associated with

C C The Author(s). 2020 Open Access This article is licensed under a Creative Commons Attribution 4.0 International License, which permits use, sharing, adaptation, distribution and reproduction in any medium or format, as long as you give appropriate credit to the original author(s) and the source, provide a link to the Creative Commons licence, and indicate if changes were made. The images or other third party material in this article are included in the article's Creative Commons licence, unless indicated otherwise in a credit line to the material. If material is not included in the article's Creative Commons licence and your intended use is not permitted by statutory regulation or exceeds the permitted use, you will need to obtain permission directly from the copyright holder. To view a copy of this licence, visit http://creativecommons.org/licenses/by/4.0/ The Creative Commons Public Domain Dedication waiver (http://creativecommons.org/publicdomain/zero/1.0/) applies to the data made available in this article, unless otherwise stated in a credit line to the data. 
impaired postoperative functional results (anal incontinence, low anterior resection syndrome, [11] and ultimately an increased rate of permanent stomata (reaching nearly $30 \%)$ ) [12-14]. Furthermore, AL is also associated with impaired oncological results with increased local and/or distal recurrence rates as well as decreased overall survival rates [15-17]. However, it is important to discriminate symptomatic from asymptomatic AL since these two conditions do not seem to have the same oncological and functional postoperative outcome [16]. Although several previous studies did not find a difference between without (AL) and asymptomatic anastomotic leakage (AAL) with regard to early postoperative functional and oncological outcome, these studies did not analyze and report long-term data from patients with AAL. Furthermore, these previous studies analyzed heterogeneous patient populations including also patients suffering from distant metastasis $[11,12,18]$. It is obvious that the inclusion of such patients has a negative impact on anastomotic healing rates, increases the risk for a permanent stoma and reduced recurrence-free and overall survival rates, respectively [14]. Therefore, the objective of our study is to report and analyse long-term oncological and functional outcome in a homogeneous population of patients with AAL and SAL who had undergone curative surgical resection for non-distant metastatic rectal cancer in a tertiary referral centre.

\section{Methods}

\section{Study population}

Retrospective study at a single tertiary referral center of patients who underwent curative intended surgery for adenocarcinoma of the rectum (upper rectum (10 to $15 \mathrm{~cm}$ ); mid (5 to $10 \mathrm{~cm}$ ); low (2 to $5 \mathrm{~cm}$ ) from the anal verge) between January 2005 to December 2017. Patients suffering from distant metastatic disease or local tumor extension requiring resection of adjacent organs (genito-urinary or vascular structures) were excluded. Further exclusion criterion was underlying inflammatory bowel disease, familial adenomatous polyposis, or pelvic recurrence after primary surgery. Data were collected from medical records for each patient and included demographic parameters, primary tumor characteristics, neoadjuvant treatment, intraoperative and pathology variables, as well as short-term and long-term oncological and functional outcomes.

\section{Neoadjuvant treatment}

Rectal cancer staging included digital rectal examination, recto-sigmoidoscopy, total colonoscopy, endorectal ultrasound and/or pelvic resonance imaging (MRI). All patients had thoraco-abdominal computed tomography (CT-scan). The upper (L5/S1 vertebrae) and the lower (levator ani/ anal verge) tumor limit was assessed by MRI and/or endorectal ultrasound, respectively. Neoadjuvant therapy consisted of either long-course treatment or short-course radiotherapy. In case of combined radio-chemotherapy (CRT), patients received 50 Gray (Gy) radio-therapy given in 25 fractions over five weeks with concomitant chemotherapy using Capecitabine (Xeloda $\left.{ }^{\circ}\right)$. Surgery was scheduled eight to 10 weeks after the end of combined radiochemotherapy [19]. Short-course radiotherapy included 25 Gy delivered in five fractions over a time span of five to seven days [20] followed by curative surgery one week later [21].

\section{Surgical procedures}

All patients had preoperative mechanical bowel preparation [22]. Laparoscopic tumor resection was the standard approach. However, patients with T4 tumors underwent primary open tumor resection. A medial-to-lateral approach was the technique of choice. The inferior mesenteric vein was ligated at the inferior border of the pancreas, followed by the mobilization of the left colon, the splenic flexure (the extend of mobilization was left at discretion of the surgeon) and ligation of the inferior mesenteric artery. If possible, the left colic artery was preserved. The rectum was transected by the use of liner stapler in double stapling technique. The proximal colon was transected approximately $10 \mathrm{~cm}$ above the upper border of the tumor. The specimen was retrieved from the abdominal cavity via a small abdominal incision [23]. Mechanical colorectal or manual colo-anal anastomoses (side-to-end or end-to-end) were performed depending on tumor level. Patients with rectal cancer of the upper rectum underwent partial mesorectal excision with a distal 5 $\mathrm{cm}$ margin from the lower border of the tumor. All other patients underwent standard TME. In case of very low rectal cancer, a total or partial intersphincteric resection was performed when ever feasible [7]. A closed suction drainage was placed in the small pelvis for 48 to $72 \mathrm{~h}$ postoperatively. A protective stoma (ileostomy) was performed routinely. In selected patients with upper rectal cancer with no neoadjuvant radio-chemotherapy, and the intraoperative conditions were assessed by the surgeon as favorable, no deviation ileostomy was placed.

\section{Short-term outcomes}

Any postoperative clinical (sepsis, peritonitis, emission of gas, pus, or feces from the pelvic drain, purulent discharge per anus, or rectovaginal fistula) and/or biological suspicion (increased CRP and white blood cells count) of $\mathrm{AL}$ led to an earlier CT-scan assessment. In case of asymptomatic $\mathrm{AL}$, antibiotic treatment was given to all patients. If required, CT-scan guided, trans-anal drainage placement or even redo-surgery was performed. After hospital discharge, all patients underwent structured outpatient follow-up including physical examination, routine 
blood tests (including CRP) and a CT-scan with watersoluble contrast enema within three months postoperatively. Anastomotic leakage was defined and graded according to the International Study Group of Rectal Cancer [24]. Patients were divided in three groups as follows: symptomatic AL (SAL, including grade $B$ and $C$ ALs), asymptomatic radiologic AL (AAL, diagnosed on enema-contrast CT-scan, routinely performed 6 to 8 weeks postoperatively, before considering stoma reversal) and without AL (WAL). Ileostomy closure was scheduled six to eight weeks postoperatively if a control CT-scan with water soluble contrast enema showed no AL. In patients with AAL, stoma reversal was delayed until CTscanning results showed no signs for AL or after a time interval of at least 6 months following rectal resection, as described recently [18]. Short-term 30 -day postoperative complications were graded according to the DindoClavien Classification [25]. In-hospital stay was measured from the day of surgery including the day of hospital discharge.

\section{Pathological results}

Surgical specimens were analyzed using a standardized protocol [26]. Tumors were staged using the TNM classification according to the 8th edition of American Joint Committee of Cancer (AJCC). Circumferential and distal margins were defined as positive $\left(R_{+}\right)$when $1 \mathrm{~mm}$ or less (primary tumor nodes or tumor deposit within the mesorectum) and as negative (R0) when greater than 1 $\mathrm{mm}$. Total or partial mesorectal excision, colloid component degree, differentiation grade as well as presence of vascular, lymphatic or peri nervous emboli were stated in pathology report.

\section{Long-term outcomes}

Long-term functional and oncological outcomes were recorded in all patients. Patient follow-up was performed every 3 months for the first 2 postoperative years, every 6 months for the next 3 years and then annually thereafter. Follow-up was updated until December 2018 and consisted of clinical examination, CT-scan, and blood tests with colonoscopy performed one and then every 3 years after surgery. Local recurrence was defined as tumor recurrence at the anastomotic site or in the pelvic cavity, while distant recurrence was defined as tumor recurrence beyond the loco-regional area including liver, lung and/or other extra pelvic sites. Follow-up data was obtained from medical records, outpatient clinic or phone interview. Long-term functional genito-urinary and digestive outcomes as well as quality of life assessments were recorded using a French translation of the low anterior resection score [27], the Wexner continence grading scale [28], the IIEF-5 erectile dysfunction score [29], the SF36 health survey [30], a French validated version of the European Organization for Research and Treatment of Quality of Life Questionnaire for Colorectal Cancer (EORTC QLQ-CR30) [31], the EUROQOL non disease-specific instrument for evaluation healthrelated quality of life [32] and the Fecal Incontinence Quality-of-life (FIQL) scale [33]. All previously mentioned surveys and questionnaires were collected in outpatient clinic or by phone interview whenever possible. For all functional scales, a greater score represented a more impaired quality of life and for all symptom scales, a greater score was associated with a greater severity of symptoms. Furthermore, surgery-related long-term complications such as small bowel occlusion, anastomosis stenosis and incisional hernias were also recorded. Patients who were unable to undergo protective stoma reversal and those who required secondary stoma placement (colostomy or ileostomy) after protective stoma reversal were also identified. Pathological response to neoadjuvant chemotherapy was considered partial if any tumor downstaging was noted on specimen, total if no residual tumor was found and absent if no downstaging was noted.

\section{Statistical analysis}

Baseline and demographic characteristics of the studied population, intraoperative and pathological characteristics as well as short- and long-term postoperative outcomes were analyzed. Patients who presented with SAL, AAL and without AL (WAL) were compared. Categorical variables were compared using the $x 2$ test with Bonferroni correction whenever necessary. The Kaplan-Meier method was used to estimate recurrence-free survival (RFS) and overall survival (OS), which were compared using the Log-rank test. All statistical analyses were performed using SPSS version 20.0 (SPSS Inc., Chicago, IL) and statistical significance was accepted at the 0.05 level. Continuous variables were compared using ANOVA or nonparametric ANOVA tests, accordingly. Significant prognostic factors associated with permanent stoma were identified by univariable logistic regression and included in a multivariable analysis to determine independent risk factors. This study was conducted according to the ethical standards of the Committee on Human Experimentation of our institution and reported according to the Strengthening the Reporting of Observational Studies in Epidemiology (STROBE) guidelines [34].

\section{Results}

\section{Patients' characteristics}

During the study period, 747 patients underwent surgery for rectal cancer in our department. Among these patients, 247 (33\%) presented with synchronous metastasis (i.e. liver, pulmonary, peritoneal and/or other organs) and $300(40 \%)$ underwent abdominoperineal resection and/or combined organ resection, and were therefore 
excluded. A total of 200 patients who underwent sphincter-preserving resection with curative intent for upper (53 patients $(26.5 \%))$, mid (105 patients $(52.5 \%))$ and low (42 patients (21.0\%)) rectal adenocarcinoma, were included. Patients' baseline characteristics are reported in Table 1. Overall, there were 137 (67.5\%) men with a median age of 67 (IQR 59-73) years. Patients' comorbidities were comparable between the three groups (ASA score, $p=0.306$ ). Neoadjuvant therapy was administered in $150(75.0 \%)$ patients, of whom $138(92.0 \%)$ underwent long-course radiation therapy and $12(8.0 \%)$ short-course radiation therapy, with no differences found between the SAL, AAL and WAL group $(p=$ 0.855). Overall, 188 (94.0\%) patients underwent laparoscopic procedure of whom $45(22.5 \%)$ required conversion with no differences noted between the three groups ( $p=0.707$ vs $p=0.827)$. Total mesorectal excision was performed in $149(74.5 \%)$ patients with no differences found between the three groups $(p=0.438)$. In patients sufering from low rectal adenocarcinoma, 9/42 patients underwent intersphinteric resection (one total and 8 partial) and 29/42 patients had a manual coloanal anastomosis with no differences found between the three groups ( $p=0.885$ vs $p=0.296$ ). A diverting stoma was placed in 179 (89.5\%) patients with no differences found between the three groups $(p=0.735)$. Detailed intraoperative variables are reported in Table 2 .

\section{Short-term postoperative outcomes}

Postoperative AL occurred in 39 (19.5\%) patients of whom 29 (14.5\%) had SAL and 10 (5.0\%) AAL. Stoma details in the different analysed groups are summarized in Fig. 1. Postoperative mortality rate in the total study population was nil. In the SAL group, sepsis was the main symptom in $25(86.2 \%)$ patients. Additinonally, in four $(13.8 \%)$ other SAL patient's ileus $(n=2)$ and anal pus discharge $(n=2)$ were the only clinical symptoms observed. Symptomatic AL was diagnosed after a median of 10 (5.5-16.0) days postoperatively. Redo abdominal surgery was performed after a median of 7 (IQR 6.316.8) days in $12(41.4 \%)$ patients (anastomosis resection and colostomy placement $(n=6)$ and peritoneal lavage

Table 1 Demographic and perioperative characteristics

\begin{tabular}{|c|c|c|c|c|c|}
\hline \multirow[t]{2}{*}{ N (\%) } & Overall population & Symptomatic AL (SAL) & Asymptomatic AL (AAL) & Without AL (WAL) & $P$ \\
\hline & $200(100)$ & $29(14.5)$ & $10(5.0)$ & $161(80.5)$ & \\
\hline Age (years). median \pm IQR & $67(59-73)$ & $67(58-73)$ & $70(67-78)$ & $66(59-73)$ & \\
\hline$\geq 60$ years. $n(\%)$ & $145(72.5)$ & $21(72.4)$ & $8(80.0)$ & $116(72.0)$ & 0.526 \\
\hline < 60 years. $\mathrm{n}(\%)$ & $55(27.5)$ & $8(27.6)$ & $2(20.0)$ & $45(28.0)$ & \\
\hline Sex ratio (Female/Male) & $65 / 135$ & $7 / 22$ & $3 / 7$ & $55 / 106$ & 0.561 \\
\hline $\mathrm{BMI}(\mathrm{kg} / \mathrm{m} 2)$. median $\pm \mathrm{IQR}$ & $24(23-28)$ & $24(23-26)$ & $30(25-34)$ & $24(23-27)$ & 0.017 \\
\hline \multicolumn{6}{|l|}{ ASA Score. n (\%) } \\
\hline 1 & $107(53.5)$ & $16(55.2)$ & $2(20.0)$ & $89(55.3)$ & \\
\hline 2 & $79(39.5)$ & $11(37.9)$ & $7(70.0)$ & $61(37.9)$ & 0.306 \\
\hline 3 & $14(7.0)$ & $2(6.9)$ & $1(10.0)$ & $11(6.8)$ & \\
\hline Arteriopathy. n (\%) & $16(8.0)$ & $2(6.9)$ & $2(20.0)$ & $12(7.5)$ & 0.355 \\
\hline Diabetes. n (\%) & $23(11.4)$ & $4(13.8)$ & $1(10.0)$ & $18(11.2)$ & 0.862 \\
\hline \multicolumn{6}{|l|}{ Tumor diagnosis. n (\%) } \\
\hline Screening test & $41(20,5)$ & $8(27.6)$ & $1(10.0)$ & $32(19.9)$ & 0.447 \\
\hline Symptoms & $159(79.5)$ & $21(72.4)$ & $9(90.0)$ & $129(80.1)$ & \\
\hline \multicolumn{6}{|c|}{ Rectal adenocarcinoma location, n (\%) } \\
\hline Upper (10-15 cm) & $53(26.5)$ & $5(17.2)$ & $1(10.0)$ & $47(29.2)$ & \\
\hline $\operatorname{Mid}(5-10 \mathrm{~cm})$ & $105(52.5)$ & $18(62.1)$ & $8(80.0)$ & $79(49.1)$ & 0.308 \\
\hline $\operatorname{Low}(2-5 \mathrm{~cm})$ & $42(21.0)$ & $6(20.7)$ & $1(10.0)$ & $35(21.7)$ & \\
\hline \multicolumn{6}{|c|}{ Neoadjuvant radiation therapy, n (\%) } \\
\hline $\begin{array}{l}\text { Long-course radiotherapy } \\
\text { (with chemotherapy) }\end{array}$ & $138(69,0)$ & $19(65.5)$ & $8(80.0)$ & $111(68.9)$ & \\
\hline $\begin{array}{l}\text { Short-course radiotherapy } \\
\text { (without chemotherapy) }\end{array}$ & $12(6.0)$ & $2(6.9)$ & 0 & $10(6.2)$ & 0.855 \\
\hline None & $50(25.0)$ & $8(27.6)$ & $2(20.0)$ & $40(24.8)$ & \\
\hline
\end{tabular}

$A L$ Anastomotic leak, SAL symptomatic AL, AAL asymptomatic AL and WAL without AL; ASA American Society of Anesthesiologists, BMI body mass index, IQR interquartile range 
Table 2 Operative details

\begin{tabular}{|c|c|c|c|c|c|}
\hline \multirow[t]{2}{*}{ N (\%) } & Overall Population & Symptomatic AL (SAL) & Asymptomatic AL (AAL) & Without $\mathrm{AL} \mathrm{AL)}$ & \multirow[t]{2}{*}{$P$} \\
\hline & $200(100)$ & $29(14.5)$ & $10(5.0)$ & $161(80.5)$ & \\
\hline Laparoscopic, n (\%) & $188(94.0)$ & $27(93.1)$ & $10(100.0)$ & $151(93.8)$ & 0.707 \\
\hline Conversion to laparotomy & $45(22.5)$ & $6(20.7)$ & $3(30.0)$ & $36(22.3)$ & 0.827 \\
\hline Complete TME, n (\%) & $149(74.5)$ & $22(75.9)$ & $8(80.0)$ & $119(73.9)$ & 0.438 \\
\hline PME, n (\%) & $51(25.5)$ & $7(24.1)$ & $2(20.0)$ & $42(26.1)$ & \\
\hline Rectal anastomosis technique, n (\%) & & & & & 0.310 \\
\hline Latero - terminal & $93(46.5)$ & $13(44.8)$ & $7(70.0)$ & $73(45.3)$ & \\
\hline Termino - terminal & $107(53.5)$ & $16(55.2)$ & $3(30.0)$ & $88(54.7)$ & \\
\hline Colo anal manual anastomosis, n (\%) & $29(14.5)$ & $5(17.2)$ & 0 & $24(14.9)$ & 0.296 \\
\hline \multicolumn{6}{|l|}{ Intersphincteric resection (ISR), n (\%) } \\
\hline Total ISR & $1(0.5)$ & 0 & 0 & $1(0.6)$ & 0.885 \\
\hline Partial ISR & $8(4)$ & $1(3.4)$ & 0 & $7(4.3)$ & \\
\hline Diverting stoma, n (\%) & $179(89.5)$ & $25(86.2)$ & $10(100.0)$ & $144(89.4)$ & 0.735 \\
\hline
\end{tabular}

AL Anastomotic leak, SAL symptomatic AL, AAL asymptomatic AL and WAL without AL, TME Total mesorectal excision; PME Partial mesorectal excision

with anastomosis repair and drainage $(n=6))$. Three patients suffered from one or more organ dysfunctions after redo surgery and had therefore to be admitted to the intensive care unit. Trans-anal drainage was performed in 5 (17.2\%) patients under general anesthesia. Overall, 11 (37.9\%) patients were managed with antibiotics only. A permanent stoma was required in $13(44.8 \%)$ patients (colostomy $(n=6)$, ileostomy $(n=7))$.

The diagnosis of AAL was made by CT-scan after a median of 40 (IQR 69-194) days postoperatively. Three (30.0\%) patients had stoma reversal before AAL was diagnosed (systematic CT-scan before reversal did not

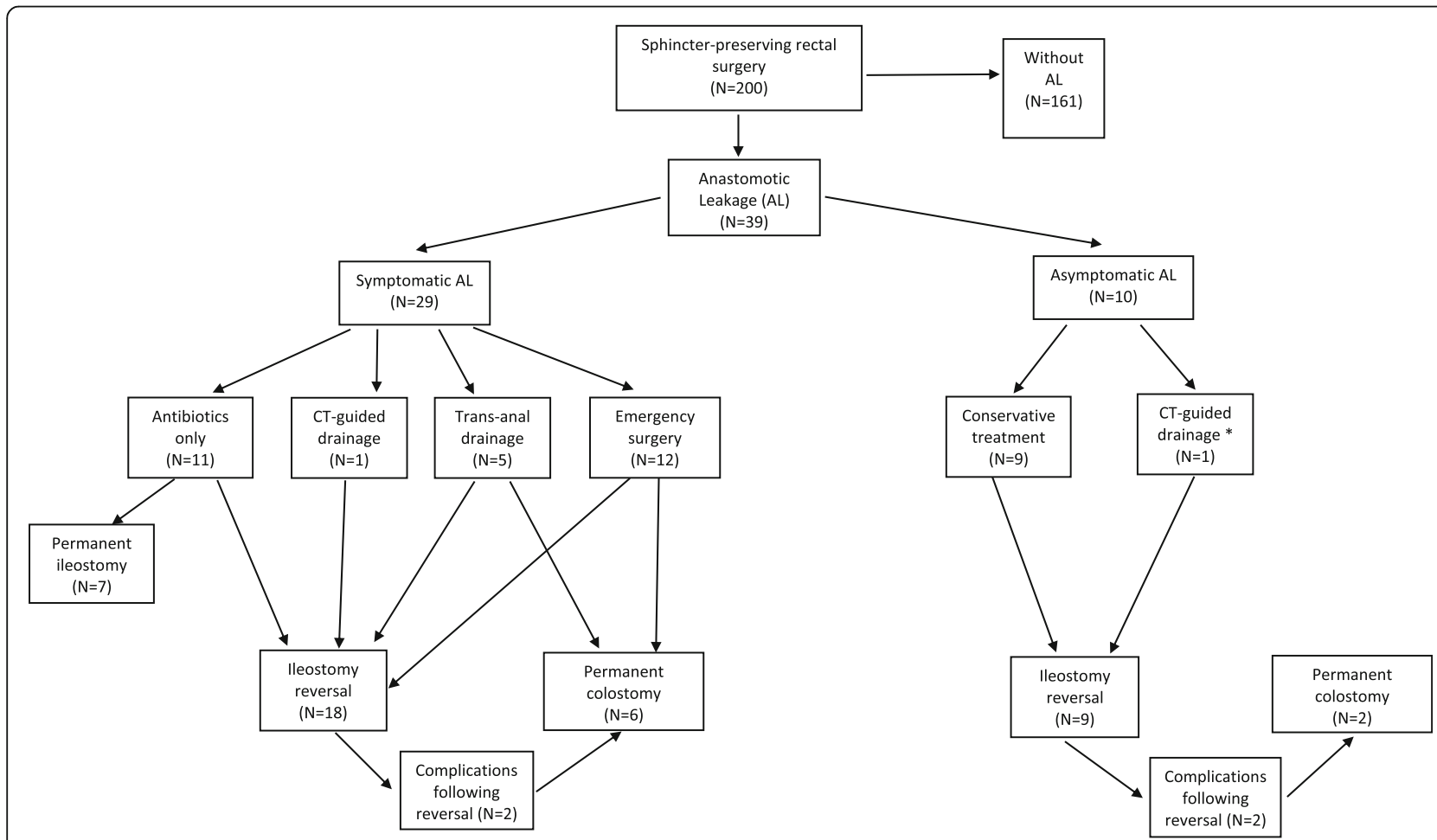

Fig. 1 Short- and long-term postoperative outcome of all patients who underwent sphincter-preserving rectal cancer surgery. Symptomatic anastomosis leakage (SAL), acute management as well as asymptomatic anastomotic leakage (AAL) management is shown below. ${ }^{*}$ One patient was diagnosed with AAL although presenting with pelvic collection on CT-scan and underwent CT-guided drainage 
show signs of AL). Seven patients (70.0\%) had AAL diagnosed before reversal. CT-scan drainage was required in one patient while the other 9 patients were treated conservatively with antibiotics only. Overall, nine patients underwent stoma reversal, of which 2 required permanent colostomy placement due to persistent fistula associated with unsatisfactory functional results. A total of three patients (30\%) finally required a permanent stoma.

There were $18(62.1 \%)$ patients who presented with severe postoperative complications in SAL group, with none in the AAL group and 9 (5.6\%) patients without $\mathrm{AL}(p<0.001)$. Severe postoperative complications in patients without AL occurred in 2 patients which had finally to undergo redo surgery for evisceration and small bowel ileus both on postoperative day seven.

A total of 161 (80.5\%) patients were without AL (WAL group). Among WAL patients, 15 (9.3\%) patients required permanent stoma placement (colostomy due to pelvic local tumor recurrence $(n=3)$, colostomy for perforation after dilatation of a anastomotic stenosis $(n=1)$ and ileostomy related to severe anastomosis stenosis $(n=11))$. Postoperative details are summarized in Table 3 and in Fig. 1.

A primary diverting stoma reversal was perfomed in 132 (91.7\%) patients without AL, 9 (90\%) patients with AAL, and $18(72 \%)$ patients with SAL, respectively $(p=$ $0.021)$. The time intervall from primary surgery to stoma closure was similar in patients with SAL (209.0 (IQR 127.3-327.3)) and patients with AAL (208.0 (IQR 115.7274.7)). However, this time span was significantly longer compared to patients without AL (91.9 (IQR 69.9-138.4) days, $p<0.001)$. Overall, complete and partial pathological responses were recorded in $28(14.0 \%)$ and 113 (56.5\%) patients with no differences observed between the three groups $(p=0.479)$. Resection margins were considered incomplete in $9(4.5 \%)$ patients with again no differences between the three groups $(p=0.151)$. In patients without $\mathrm{AL}$, three patients underwent colostomy placement after local pelvic tumor recurrence whereas one patient required colostomy due to a postinterventinal colonic perforation after dilatation of the stenotic anastomosis. Furthermore, another eleven other patients required an ileostomy for severe anastomotic stenosis.

\section{Long-term oncological outcomes}

During the postoperative follow-up, after a median time interval of 10.7 months (IQR 8.8-18.8) after curative surgery, local and distal recurrences occurred in $10(5.0 \%)$ and $34(17.0 \%)$ patients, resepectively. No differences were found between the three groups $(p=0.170)$. Oncological results are detailed in Table 4 . There were no patients in the AAL group who presented with local or distal recurrence. Disease-free survival comparison was therefore performed between the SAL and WAL group. No significant difference was observed. The 3-year disease-free survival rate was $86.6 \%$ for patients with SAL, $100 \%$ for those with AAL and $76 \%$ for those without AL $(p=0.480)$. At 5 years, the disease-free survival rate was similar in the three groups 84,100 and $70 \%$, respectively $(\mathrm{p}=0.480)$. Overall, $52(26.0 \%)$ patients underwent postoperative chemotherapy with no difference between the three groups $(p=0.465)$. Median follow-up was 38.0 months (0.7-151.5) and long-term mortality rate was $12.5 \%(n=25)$ with no difference between the three groups ( $p=0.743$ and $p=0.543$, respectively). Eight percent of patients died during follow-up from cancer progression $(n=16)$ and nine patients $(4.5 \%)$ from other causes. The 3-year overall survival rate for

Table 3 Early postoperative outcome

\begin{tabular}{|c|c|c|c|c|c|}
\hline \multirow[t]{2}{*}{ N (\%) } & Overall Population & Symptomatic AL (SAL) & Asymptomatic AL (AAL) & Without AL (WAL) & $P$ \\
\hline & $200(100)$ & $29(14.5)$ & $10(5.0)$ & $161(80.5)$ & \\
\hline Emergency surgery, n (\%) & $21(11.5)$ & $12(41.4)$ & 0 & $9(5.6)$ & \\
\hline Laparoscopic abdominal drainage, n (\%) & $3(1.5)$ & $3(10.3)$ & 0 & 0 & \\
\hline Open abdominal drainage, n (\%) & $5(2.5)$ & $3(10.3)$ & 0 & $2(1.2)$ & 0.001 \\
\hline Hartmann's procedure, n (\%) & $6(3.0)$ & $6(20.7)$ & 0 & 0 & \\
\hline Ileostomy repair, n (\%) & $7(3.5)$ & 0 & 0 & $7(4.3)$ & \\
\hline Trans-anal drainage, n (\%) & $5(2.5)$ & $5(17.2)$ & 0 & 0 & \\
\hline CT-guided drainage, $\mathrm{n}(\%)$ & $2(1.0)$ & $1(3.4)$ & $1(10,0)$ & 0 & 0.003 \\
\hline Antibiotics treatment only, n (\%) & $23(11.5)$ & $11(37.9)$ & $9(90.0)$ & 0 & - \\
\hline Hospital stay (days) median \pm IQR & $11.0(9.0-16.0)$ & $19.0(14.0-33.0)$ & $11.5(9.5-14.8)$ & $10.0(9.0-14.0)$ & $<0.001$ \\
\hline \multicolumn{6}{|l|}{ Initial diverting stoma reversal, n (\%) } \\
\hline Yes & $159(88.8)$ & $18(72.0)$ & $9(90.0)$ & $132(91.7)$ & \\
\hline No & $20(11.2)$ & $7(28.0)$ & $1(10.0)$ & $12(8.3)$ & 0.021 \\
\hline Days before stoma reversal (days), median $\pm I Q R$ & $97.0(74,1-188.2)$ & $209.0(127.3-327.3)$ & $208.0(115.7-274.7)$ & $91.9(69.9-138.4)$ & $<0.001$ \\
\hline
\end{tabular}

AL Anastomotic leak, SAL symptomatic $\mathrm{AL}, A A L$ asymptomatic $\mathrm{AL}$ and $W A L$ without $\mathrm{AL}, I Q R$ interquartile range 
Table 4 Pathology results

\begin{tabular}{|c|c|c|c|c|c|}
\hline \multirow[t]{2}{*}{ N (\%) } & Overall Population & Symptomatic AL (SAL) & Asymptomatic AL (AAL) & Without AL (WAL) & $P$ \\
\hline & $200(100)$ & $29(14.5)$ & $10(5.0)$ & $161(80.5)$ & \\
\hline \multicolumn{6}{|l|}{ T stage, n (\%) } \\
\hline T0 & $28(14.0)$ & $2(6.9)$ & $2(20.0)$ & $24(14.9)$ & 0.460 \\
\hline $\mathrm{T} 1$ & $30(15.0)$ & $5(17.2)$ & 0 & $25(15.5)$ & \\
\hline $\mathrm{T} 2$ & $57(28.5)$ & $7(24.1)$ & $5(50.0)$ & $45(27.9)$ & \\
\hline T3 & $78(39.0)$ & $14(48.3)$ & $2(20.0)$ & $62(38.5)$ & \\
\hline T4 & $7(3.5)$ & $1(2.9)$ & $1(10.0)$ & $5(3.1)$ & \\
\hline \multicolumn{6}{|l|}{ N stage, n (\%) } \\
\hline $\mathrm{N}+$ & $48(24.0)$ & $5(17.2)$ & $2(20.0)$ & $41(25.5)$ & 0.594 \\
\hline NO & $152(76.0)$ & $24(82.8)$ & $8(80.0)$ & $120(74.5)$ & \\
\hline \multicolumn{6}{|l|}{ Pathological response, n (\%) } \\
\hline Absent & $59(28.5)$ & $11(38.0)$ & $1(10.0)$ & $47(29.2)$ & \\
\hline Partial & $113(56.5)$ & $17(58.6)$ & $7(70.0)$ & $89(55.3)$ & 0.479 \\
\hline Complete & $28(14.0)$ & $1(3.4)$ & $2(20.0)$ & $25(15.5)$ & \\
\hline Lymph nodes, median \pm IQR & $18.0(13.0-25.5)$ & $18.0(12.5-23.5)$ & $18.5(15.0-25.0)$ & $17.5(13.0-26.0)$ & 0.593 \\
\hline Tumor diameter $(\mathrm{mm})$, median $\pm I Q R$ & $25.5(20.0-35.5)$ & $27.5(20.0-35.0)$ & $30.0(22.5-37.5)$ & $25.0(18.0-35.0)$ & 0.971 \\
\hline \multicolumn{6}{|l|}{ Resection margins, n (\%) } \\
\hline Incomplete (R+) & $9(4.5)$ & $3(10.3)$ & $1(10.0)$ & $5(3.1)$ & \\
\hline Complete (RO) & $191(95.5)$ & $26(89.7)$ & $9(90.0)$ & $156(96.9)$ & 0.151 \\
\hline
\end{tabular}

AL Anastomotic leak, SAL symptomatic $\mathrm{AL}, A A L$ asymptomatic $\mathrm{AL}$ and WAL without $\mathrm{AL}, I Q R$ interquartile range

patients in the SAL group was $82.9,100 \%$ in the AAL group and $94.7 \%$ in the WAL group, resepectively ( $p=$ $0.527)$. Similarly, at 5 -years, overall survival did not differ between the three groups $(77,100$ and $88.3 \% ; \mathrm{p}=0.527$ ). Details about the overall and disease-free survival rates are presented in Fig. 2a-b.

\section{Long-term functional results}

There were $31(15.5 \%)$ patients requiring permanent stoma placement $((n=15)$ WAL group, $(n=13) \mathrm{SAL}$ group and $(n=3)$ in AAL group, $p<0.001))$. In the WAL group, three patients underwent colostomy placement after local tumoral recurrence, one patient had colostomy for perforation after stenosis dilatation and eleven patients had ileostomies related to severe anastomosis stenosis. In patients with SAL, 6 patients had permanent stoma placement after postoperative redo surgery, 2 patients required colostomy placement after soma reversal for septic complication, and 5 patients required secondary colostomy placement after soma reversal for poor functional results. In patients with AAL, one patient required a permanent stoma due to medical comorbidities (cardiac and pulmonary insufficiency) and two other patients required a secondary colostomy placement after stoma reversal with poor functional results. Furthermore, analysis over time revealed a significantly different permament stoma rate between the three groups $(p<0.001)$ as shown in Fig. 3. Long-term functional results of 42 patients are shown in Table 5 . Excluding deceased patients $(n=25)$ and patients with permanent stoma placement $(n=31)$, this represented a response rate of $28.2 \%$ for functional assessment scores. Only the Wexner continence grading scale was significantly higher in patients who presented with $\operatorname{AL}(p=$ $0.014)$. Wexner continence grading scale was also significantly different between the AAL, SAL and WAL group $(p=0.049)$. Permanent stoma rate was higher in patients with SAL compared to WAL patients $(44.8 \%$ vs $9.3 \%$, $\mathrm{p}<0.001)$ and similar compared to the AAL group $(30 \%$, $p=0.699)$. Data are summarized in Fig. 3. Overall, patients with AL $(n=39)$ had a permanent stoma rate of $41 \%$ compared to $9.3 \%$ in the WAL group $(n=161), p<$ 0.001 . Multivariate analysis showed that $\mathrm{R} 1$ resection and SAL were the only independent factors which were predictive for a permanent stoma $(\mathrm{OR}=7.001$ (1.06745.930), $p=0.043$ and $\mathrm{OR}=8.209(3.038-22.184), \mathrm{p}<$ 0.001). Data are presented in Table 6.

\section{Discussion}

In this retrospective single center study we conducted a comparative analysis of asymptomatic and symptomatic $\mathrm{AL}$ in patients who underwent rectal resection with curative intent. Both short-term and long-term morbidity, functional and oncological outcomes in this homogeneous population were analyzed. Patients suffering from SAL were found not to be at risk for an increased 


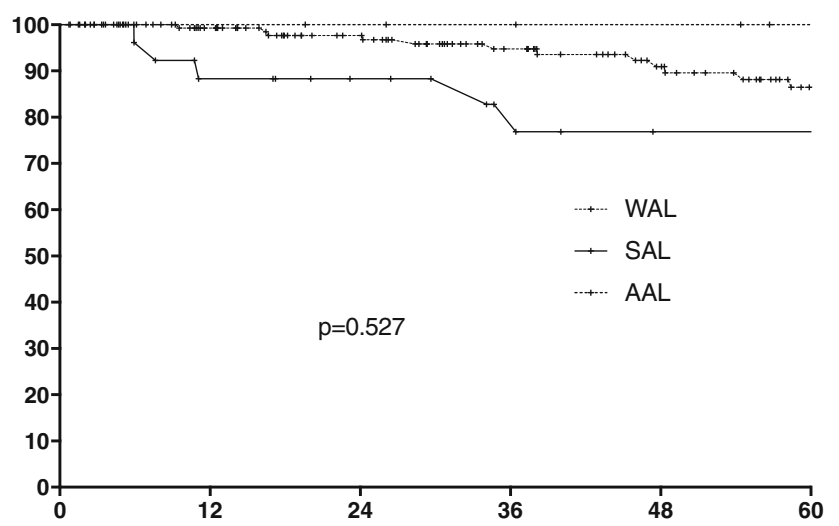

\begin{tabular}{|c|c|c|c|c|c|c|}
\hline No. at risk & & & & & & \\
\hline Symptomatic leakage & 29 & 23 & 19 & 15 & 12 & 12 \\
\hline Asymptomatic leakage & 10 & 10 & 9 & 8 & 7 & 5 \\
\hline No leakage & 161 & 132 & 110 & 86 & 69 & 50 \\
\hline
\end{tabular}

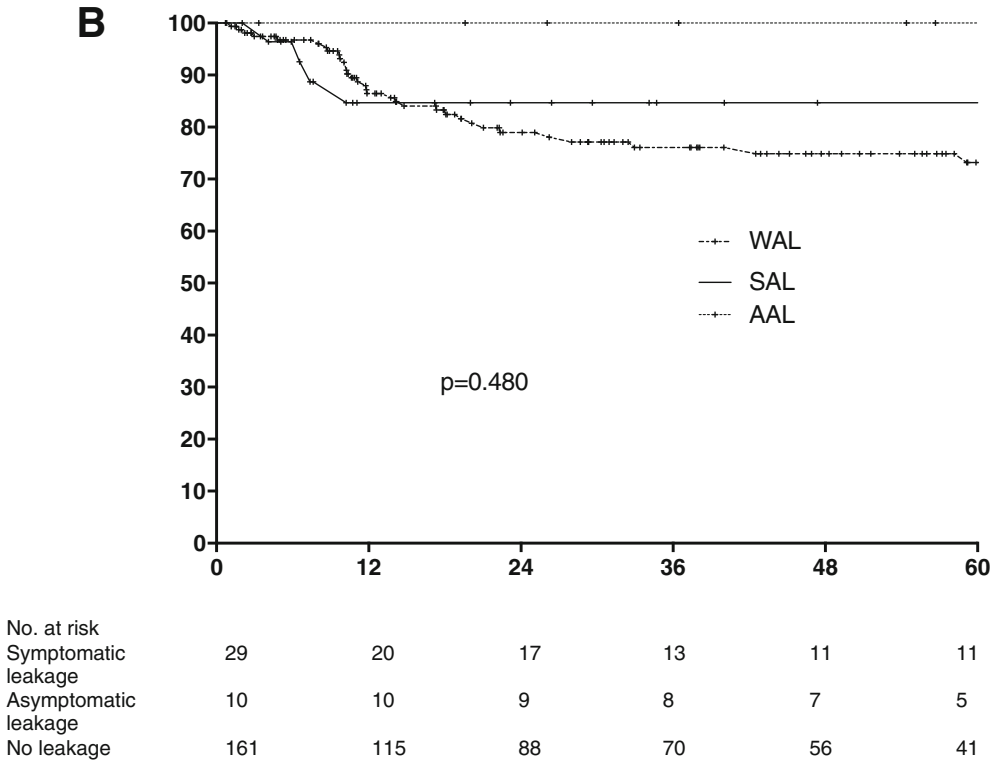

Fig. 2 a Symptomatic anastomotic leak (SAL) group (solid line) and asymptomatic AL (AAL) group (Point line), without AL (WAL) group (Dash lines) Overall survivals in SAL, AAL and Without AL. Anastomotic leak (AL) groups symptomatic $A L(S A L)$, asymptomatic $A L$ (AAL) and without AL (WAL). X axis: months. Y axis: percentage survival. b Symptomatic anastomotic leak (SAL) group (solid line) and asymptomatic AL (AAL) group (Point line), without AL (WAL) group (Dash lines). Disease free survival in $S A L, A A L$ and Without $A L$. Anastomotic leak (AL) groups symptomatic AL $(\mathrm{SAL})$, asymptomatic $\mathrm{AL}(\mathrm{AAL})$ and without $\mathrm{AL}(\mathrm{WAL})$. $\mathrm{X}$ axis: month. Y axis: percentage survival

number of local and/or distant tumor recurrence rates compared to the group of AAL and WAL patients. However, in the group of patients suffering from postoperative anastomotic leakage (AAL and SAL) we observed an impaired long-term outcome of postoperative functional results. Furthermore, there is an increased risk for a permanent stoma in AAL and SAL patients which is as high as $41 \%$ and compated to patients with no postoperative anastomotic leakage (9.3\%) is significantly higher.

The effect of postoperative anastomotic leakage (AL) on the oncological outcome following rectal cancer surgery is still debated controversially and remains unclear. Some authors have reported about reduced local recurrence rates whereas distant recurrence rates and overall survival rates were found to be similar. In contrast, equivalent local, distant disease recurrence rates and overall survival rates were observed by others $[15,35,36]$. Furthermore, two meta-analysis reported that $\mathrm{AL}$ was associated with higher local disease recurrence rates and reduced long-term cancer specific survival. No impact was found on the incidence of distant disease recurrence rates $[15,35]$. Moreover, five pooled 


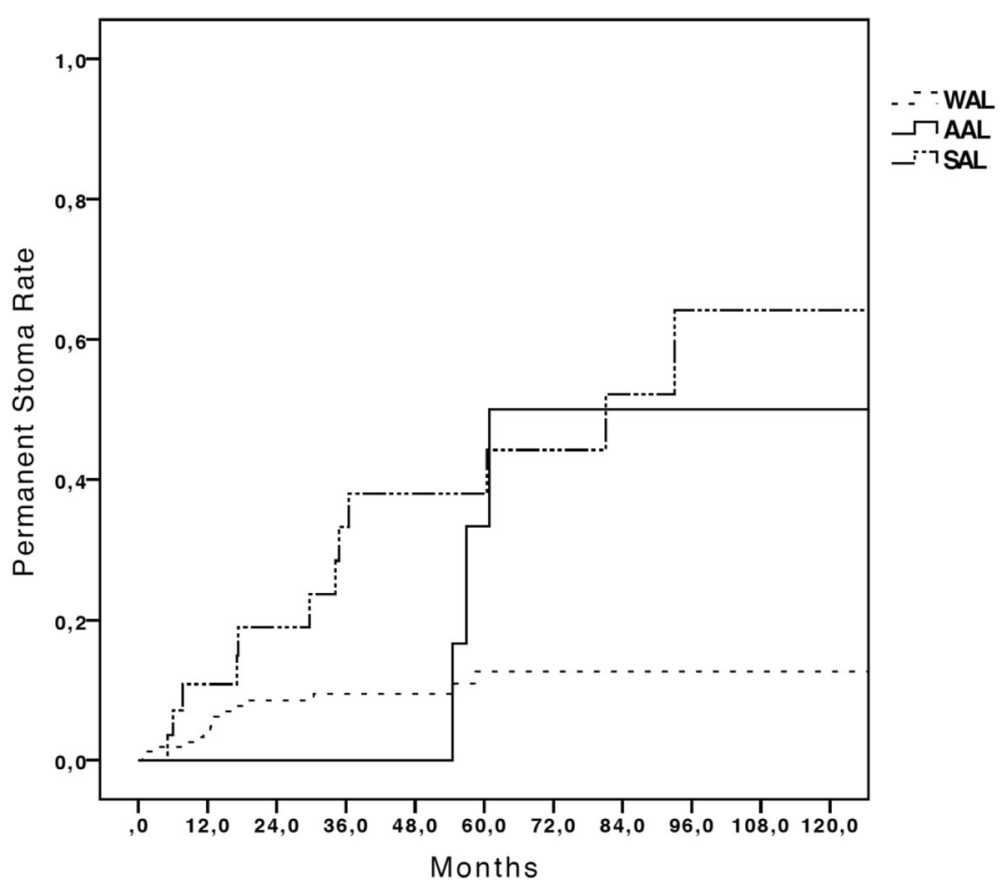

Fig. 3 Permanent stoma rate determined as a time to event analysis in SAL, AAL and Without AL. Anastomotic leak (AL) groups symptomatic AL $(\mathrm{SAL})$, asymptomatic $\mathrm{AL}(\mathrm{AAL})$ and without $\mathrm{AL}(\mathrm{WAL}) . \mathrm{X}$ axis: month. $Y$ axis: cumulative percentage of patients with permanent stoma

randomized trials [36] published in 2009 concluded that the disease-free survival was not affected by the postoperative appearance of symptomatic AL. However, symptomatic AL was observed to be associated with an impaired overall survival in such patients. Such discrepancies between the reported results in the aforementioned studies might be be explained by considering two important facts about postoperative AL in more detail.

First, in most previously published studies, any clinical impact of postoperative AAL was not assessed since no discrimination between AAL and SAL was made. So far, only a few studies analyzed the subgroup of AAL and observed that the short- as well as the and long-term outcome differed from the SAL and WAL group, respectively [16].

Second, the diagnosic work-up, definition of AAL and also the discrimination from patients without AL are still not clearly defined and are controversially discussed. Therefore it is obvious that the rate of patients with diagnosed postoperative AL varies considerably between the different studies with a reported prevalence which is somewhere in the range between $5 \%$ [37-39] to $28 \%$ [11-16].

In this present study, we observed an incidence of $\mathrm{AL}$ of $18 \%(39 / 200)$ which is indeed somewhat higher compared to other studies [37-39]. However, our findings could be explained by the fact that all patients in our study were subjected to AL screening which, in accordance with the recommendations of the working group of
Panis et al., included routine blood testing and water soluble enema contrast CT-scan six weeks postoperatively and before stoma reversal [11-16].

In contrast to the study published by Hain et al. [16] we observed no significant difference of the overall and disease-free survival between the AAL, SAL and WAL group, respectively. Indeed, we are aware that an important limitation of our study, besides that it is retrospective, is the limited number of included patients which hampers statistical data interpretation. Nevertheless, the homogeneity of our study population is an important quality criterion compared to other studies which also included patients suffering from distant metastatic disease $[16,38,39]$. Including such patients suffering from distant metastases carries a relevant risk to bias study data since such patients suffer from impaired postoperative anastomotic healing with all the corresponding known negative sequelae [14]. Finally, the management of rectal cancer has substantially improved in the last decade (i.e. rectal surgery, neoadjuvant treatment, diagnosis and treatment of $\mathrm{AL}$ ). Therefore, data from previous studies (1971 to 2010) [37-39] are not comparable to present data since they do not reflect current standards for diagnosis and treatment of rectal cancer. Hence, the interpretation of our current data in the context of such previous studies is probably of limited relevance.

Although we did not find a negative impact of SAL and AAL on the oncological outcome in our present 
Table $\mathbf{5}$ Late postoperative outcome

\begin{tabular}{|c|c|c|c|c|c|}
\hline \multirow[t]{2}{*}{$\mathrm{N}(\%)$} & Overall Population & Symptomatic AL (SAL) & Asymptomatic AL (AAL) & Without AL (WAL) & $P$ \\
\hline & $200(100)$ & $29(14.5)$ & $10(5.0)$ & $161(80.5)$ & \\
\hline \multicolumn{6}{|l|}{ Oncological results } \\
\hline Adjuvant chemotherapy, n (\%) & $52(26.0)$ & $7(24.1)$ & $1(10.0)$ & $44(27.3)$ & 0.465 \\
\hline \multicolumn{6}{|l|}{ Recurrence, n (\%) } \\
\hline Local & $10(5.0)$ & $2(6.9)$ & 0 & $8(5.0)$ & \\
\hline Distance & $34(17.0)$ & $3(10.3)$ & 0 & $31(19.3)$ & 0.170 \\
\hline Total patients with recurrence & 39 (19.5) & $4(13.8)$ & 0 & $35(21.7)$ & \\
\hline Time to recurrence (month), median $\pm I Q R$ & $10.7(8.8-18.8)$ & $7.0(6.0-8.1)$ & 0 & $11.8(9.6-19.8)$ & 0.173 \\
\hline Median of follow up (months) $\pm I Q R$ & $38.5(17.2-65.6)$ & $34.5(17.1-66.5)$ & $55.7(28.8-61.9)$ & $38.1(16.7-65.5)$ & \\
\hline Overall survival at 3 years & $95.5 \%$ & $82.9 \%$ & $100 \%$ & $94.7 \%$ & 0.527 \\
\hline Overall survival at 5 years & $91.5 \%$ & $77 \%$ & $100 \%$ & $88.3 \%$ & \\
\hline Disease free survival at 3 years & $81.5 \%$ & $86.6 \%$ & $100 \%$ & $76 \%$ & 0.480 \\
\hline Disease free survival at 5 years & $80.5 \%$ & $84 \%$ & $100 \%$ & $70 \%$ & \\
\hline \multicolumn{6}{|l|}{ Functional results } \\
\hline Permanent stoma, n (\%) & $31(15.5)$ & $13(44.8)$ & $3(30.0)$ & $15(9.3)$ & $<0.001$ \\
\hline lleostomy & $18(9.0)$ & $7(24.1)$ & $1(10.0)$ & $11(6.8)$ & \\
\hline Colostomy & $13(6.5)$ & $6(20.7)$ & $2(20.0)$ & $4(2.5)$ & \\
\hline Other late complications, n (\%) & & & & & $<0.001$ \\
\hline Stenosis & 24 & 6 & 1 & 17 & \\
\hline Hernia & 16 & 5 & 4 & 7 & \\
\hline Occlusion & 3 & 1 & 0 & 2 & \\
\hline \multicolumn{6}{|l|}{ Mean of quality of life assessments } \\
\hline LARS Score & $26,2 \pm 12,8$ & $34,3 \pm 4,0$ & $28,8 \pm 14,9$ & $25,1 \pm 13,0$ & 0.522 \\
\hline Wexner Score & $7,3 \pm 4,8$ & $10,3 \pm 0,6$ & $11,4 \pm 3,8$ & $6,4 \pm 4,7$ & 0.049 \\
\hline IIEF5 & $10,0 \pm 8,9$ & $18,0 \pm 1,4$ & $2,3 \pm 2,3$ & $10,4 \pm 9,2$ & 0.187 \\
\hline SF36 & $98,8 \pm 10,5$ & $105,0 \pm 7,9$ & $99,2 \pm 5,4$ & $98,2 \pm 11,2$ & 0.446 \\
\hline EORTC QLQ-C30 & $53,9 \pm 11,4$ & $49,3 \pm 3,2$ & $62,4 \pm 14,5$ & $53,0 \pm 11,0$ & 0.077 \\
\hline EuroQol & $69,0 \pm 18,9$ & $75,0 \pm 5,0$ & $59,0 \pm 18,2$ & $69,9 \pm 19,6$ & 0.111 \\
\hline FIQL & $86,8 \pm 20,6$ & $81,3 \pm 3,5$ & $74,2 \pm 22,0$ & $89,2 \pm 20,8$ & 0.136 \\
\hline EORTC QLQ-MY20 & $28,7 \pm 7,0$ & $28,3 \pm 1,5$ & $31,0 \pm 7,1$ & $28,4 \pm 7,4$ & 0.685 \\
\hline
\end{tabular}

AL Anastomotic leak, SAL symptomatic $\mathrm{AL}, A A L$ asymptomatic $\mathrm{AL}$ and WAL without $\mathrm{AL}, \mathrm{QQR}$ interquartile range)

Table 6 Multivariate analysis of factors associated with permanent stoma

\begin{tabular}{llll}
\hline & Odds Ratio & Cl 95\% & $\mathrm{P}$ \\
\hline Age & 1.041 & $0.989-1.097$ & 0.127 \\
ASA & & & \\
4 & 1.999 & $0.727-5.500$ & 0.180 \\
TME & 1.714 & $0.322-9.120$ & 0.528 \\
R1 & 2.586 & $0.875-7.643$ & 0.086 \\
Fistula occurrence & 7.001 & $1.067-45.930$ & 0.043 \\
Asymptomatic fistula & 3.221 & & \\
Symptomatic fistula & 8.209 & $0.718-14.456$ & 0.127 \\
\hline
\end{tabular}

study we observed an impaired short- and long-term functional outcome of AAL compared to patients without AL (WAL). This is again in contrast to a recently published study by Hain et al. which found no difference between the LARS score in the AAL, SAL, and WAL group, respectively. However, the authors of this study did not discriminate between WAL and AAL in their multivariate analysis of predictive factors of the postoperative functional outcome [11]. Although it is obvious that AL has a negative impact on the postoperative functional outcome [40-45] it remains still unclear for the subgroup of patients with AAL. Similar findings as ours were found by Lim et al. who reported that the bowel function after ileostomy closure was equally impaired in the AAL and SAL group, respectively [40]. 
In our study, the postoperative time interval to stoma reversal was similar in SSL and AAL, but significantly longer compared to WAL patients. These results are consistent with findings in other previous studies [11, 40]. Furthermore, we observed that the permanent stoma rates were quite similar in the AAL $(30 \%)$ and SAL (44.8\%) group but significantly higher compared to the WAL group (9.3\%). Some other authors have reported that all AAL patients can be managed conservatively with spontaneous healing whereas SAL patients showed only a $40 \%$ percent rate of spontaneous healing [40]. An important finding in our study is the fact that, even if AAL patients can be managed conservatively, the functional postoperative outcome can be impaired.

Our multivariate analysis revealed that SAL and R1 rectal tumor resection were the only independent risk factors for a permanent stoma. For the presence of AAL only a trend towards a higher stoma rate was found.

We are aware about some limitations of our study (small number, retrospective). Nonetheless, our study is the first which observed that AAL patients have a risk for worse postoperative functional long-term outcome and a high risk for a permanent stoma. Finally, previous studies are lacking of long-term outcome data for AAL and SAL and are heterogeneous since they also included patients suffering from distant metastatic disease [11-18].

\section{Conclusion}

In conclusion, AL did not impair long-term oncological results (disease-free and overall survival) in patients with rectal adenocarcinoma. Despite the small numbers of patients, especially in the AAL group, long-term functional results were impaired by the occurrence of SAL and AAL with a similar permanent stoma rate in both groups.

\section{Abbreviations}

TME: Total Mesorectal Excision; ASA: American Society of Anesthesiology score; EUS: Endorectal Ultrasound; MRI: Magnetic resonance imaging; CT: Cumputed tomography; RCT: Radio chemo therapy; AL: Anastomotic Leakage; SAL: Symptomatic AL; AAL: Asymptomatic AL; WAL: Without AL

\section{Acknowledgments}

The authors are deeply grateful to Katarzyna GAJ and Guillaume PROUTHEAU for their invaluable secretarial assistance.

\begin{abstract}
Authors' contributions
Study concept and design: MO, AA, NT, OI. Acquisition of data: OM, OI, AA, NM. Analysis and interpretation: MO, NT, AA. Drafting the manuscript: MO, $N T$, AA. Critical review of the manuscript: PB, UPG, AKB, TL, CBT, ES. Statistical analysis: MO, NT. Administrative, technical, and material support: MO. Study supervision: MO. All authors have read and approved the manuscript.
\end{abstract}

\section{Funding}

Source of financial support: None.

\section{Availability of data and materials}

The datasets used and analyzed during the current study are available from the corresponding author on reasonable request.

\section{Ethics approval and consent to participate}

This study was approved by the local comity of informatics and liberty (CIL) ( ${ }^{\circ}$ 2020-067). According to the French law (Code de la santé publique, Article R1121-1 Modifié par Décret n²017-884 du 9 mai 2017 - art.2) no permission of the IRB for this purely retrospective study was required. All procedures performed in studies involving human participants were in accordance with the ethical standards of the institutional and/or national research committee and with the 1964 Helsinki declaration and its later amendments or comparable ethical standards. Written informed consent was obtained from all individual participants included in the study.

\section{Consent for publication \\ Not applicable.}

\section{Competing interests}

The authors of this manuscript declare no relationships with any companies, whose products or services may be related to the subject matter of the article. Mehdi Ouaissi member of editorial board member of BMC cancer journal declare no relationships with any companies, or journals whose products or services may be related to the subject matter of the article.

\section{Author details}

'Department of Digestive, Oncological, Endocrine, Hepato-Biliary, Pancreatic and Liver Transplant Surgery, Trousseau Hospital, Chambray les Tours, Avenue de la République, Chambray les Tours, France. ${ }^{2}$ Department of General-, Visceral- and Transplant Surgery, University of Münster, Münster, Germany. ${ }^{3}$ Department of Hepatogastroenterology and Digestive Oncology, Tours, France.

Received: 17 July 2019 Accepted: 23 June 2020

Published online: 20 August 2020

\section{References}

1. Heald RJ, Husband EM, Ryall RDH. The mesorectum in rectal cancer surgery - the clue to pelvic recurrence? Br J Surg. 1982;69:613-6.

2. Kapiteijn E, Marijnen CA, Nagtegaal ID, Putter H, Steup WH, Wiggers T, et al. Preoperative radiotherapy combined with total mesorectal excision for resectable rectal cancer. N Engl J Med. 2001;345:638-46.

3. Sauer R, Becker H, Hohenberger W, Rödel C, Wittekind C, Fietkau R, et al. Preoperative versus postoperative chemoradiotherapy for rectal cancer. $\mathrm{N}$ Engl J Med. 2004;351:1731-40.

4. Bosset J-F, Collette L, Calais G, Mineur L, Maingon P, Radosevic-Jelic L, et al. Chemotherapy with preoperative radiotherapy in rectal cancer. $N$ Engl J Med. 2006:355:1114-23.

5. Martling A, Holm T, Rutqvist LE, Johansson H, Moran BJ, Heald RJ, et al. Impact of a surgical training programme on rectal cancer outcomes in Stockholm. Br J Surg. 2005;92:225-9.

6. Rullier E, Laurent C, Bretagnol F, Rullier A, Vendrely V, Zerbib F. Sphinctersaving resection for all rectal carcinomas: the end of the 2-cm distal rule. Ann Surg. 2005;241:465-9.

7. Kanso F, Maggiori L, Debove C, Chau A, Ferron M, Panis Y. Perineal or abdominal approach first during Intersphincteric resection for low rectal Cancer: which is the best strategy? Dis Colon Rectum. 2015;58:637-44.

8. Matthiessen P, Hallböök O, Rutegard J, Simert G, Sjödahl R. Defunctioning stoma reduces symptomatic anastomotic leakage after low anterior resection of the rectum for cancer: a randomized multicenter trial. Ann Surg. 2007;246:207.

9. Yeh CY, Changchien CR, Wang J-Y, Chen J-S, Chen HH, Chiang J-M, et al. Pelvic drainage and other risk factors for leakage after elective anterior resection in rectal cancer patients: a prospective study of 978 patients. Ann Surg. 2005;241:9.

10. Peeters KCMJ, Tollenaar RAEM, Marijnen CAM, Klein Kranenbarg E, Steup WH, Wiggers $T$, et al. Risk factors for anastomotic failure after total mesorectal excision of rectal cancer. Br J Surg. 2005;92:211-6.

11. Hain E, Manceau G, Maggiori L, Mongin C, la Prost A DJ, Panis Y. Bowel dysfunction after anastomotic leakage in laparoscopic sphincter-saving operative intervention for rectal cancer: A case-matched study in 46 patients using the Low Anterior Resection Score. Surgery. 2017;161:1028-39.

12. Maggiori L, Bretagnol F, Lefèvre JH, Ferron M, Vicaut E, Panis Y. Conservative management is associated with a decreased risk of definitive stoma after anastomotic leakage complicating sphincter-saving resection for rectal 
cancer: conservative management is associated with a decreased risk of definitive stoma. Color Dis. 2011;13:632-7.

13. Holmgren K, Kverneng Hultberg D, Haapamäki MM, Matthiessen P, Rutegård J, Rutegård M. High stoma prevalence and stoma reversal complications following anterior resection for rectal cancer: a population-based multicentre study. Color Dis. 2017;19:1067-75.

14. Mak JCK, Foo DCC, Wei R, Law WL. Sphincter-preserving surgery for low rectal cancers: incidence and risk factors for permanent stoma. World J Surg. 2017;41:2912-22.

15. Wang S, Liu J, Wang S, Zhao H, Ge S, Wang W. Adverse effects of anastomotic leakage on local recurrence and survival after curative anterior resection for rectal Cancer: a systematic review and meta-analysis. World J Surg. 2017;41:277-84.

16. Hain E, Maggiori L, Manceau G, Mongin C, la Prost À DJ, Panis Y. Oncological impact of anastomotic leakage after laparoscopic mesorectal excision. Br J Surg. 2017;104:288-95.

17. Espín E, Ciga MA, Pera M, Ortiz H. The Spanish rectal Cancer project. Oncological outcome following anastomotic leak in rectal surgery. Br J Surg. 2015;102:416-22.

18. Hain E, Maggiori L, Manceau G, Zappa M, la Prost À DJ, Panis Y. Persistent Asymptomatic Anastomotic Leakage After Laparoscopic Sphincter-Saving Surgery for Rectal Cancer: Can Diverting Stoma Be Reversed Safely at 6 Months? Dis Colon Rectum. 2016;59:369-76.

19. Lefevre JH, Rousseau A, Svrcek M, Parc $Y$, Simon T, Tiret E. A multicentric randomized controlled trial on the impact of lengthening the interval between neoadjuvant radiochemotherapy and surgery on complete pathological response in rectal cancer (GRECCAR-6 trial): rationale and design. BMC Cancer. 2013;13:417.

20. Ceelen WP, Van Nieuwenhove Y, Fierens K. Preoperative chemoradiation versus radiation alone for stage $\|$ and $I I I$ resectable rectal cancer. In: the Cochrane collaboration, editor. Cochrane database of systematic reviews. Chichester: Wiley; 2009. https://doi.org/10.1002/14651858.CD006041.pub2.

21. Glimelius B, Tiret E, Cervantes A, Arnold D, on behalf of the ESMO Guidelines Working Group. Rectal cancer: ESMO Clinical Practice Guidelines for diagnosis, treatment and follow-up. Ann Oncol. 2013;24(suppl 6):vi81-8.

22. Bretagnol $F$, Panis $Y$, Rullier $E$, Rouanet $P$, Berdah $S$, Dousset $B$, et al. Rectal cancer surgery with or without bowel preparation: the French GRECCAR III multicenter single-blinded randomized trial. Ann Surg. 2010;252:863-8.

23. Carmichael JC, Keller DS, Baldini G, Bordeianou L, Weiss E, Lee L, et al. Clinical Practice Guidelines for Enhanced Recovery After Colon and Rectal Surgery From the American Society of Colon and Rectal Surgeons and Society of American Gastrointestinal and Endoscopic Surgeons. Dis Colon Rectum. 2017:60:761-84

24. Rahbari NN, Weitz J, Hohenberger W, Heald RJ, Moran B, Ulrich A, et al. Definition and grading of anastomotic leakage following anterior resection of the rectum: a proposal by the international study Group of Rectal Cancer. Surgery. 2010;147:339-51.

25. Dindo D, Demartines N, Clavien P-A. Classification of surgical complications: a new proposal with evaluation in a cohort of 6336 patients and results of a survey. Ann Surg. 2004;240:205-13.

26. Washington MK, Berlin J, Branton P, Burgart LJ, Carter DK, Fitzgibbons PL, et al. Protocol for the examination of specimens from patients with primary carcinoma of the colon and rectum. Arch Pathol Laboratory Med. 2009;133: 1539-51.

27. Emmertsen $\mathrm{KJ}$, Laurberg S. Low anterior resection syndrome score: development and validation of a symptom-based scoring system for bowel dysfunction after low anterior resection for rectal cancer. Ann Surg. 2012; 255:922-8.

28. Vaizey CJ, Kamm MA, Turner IC, Nicholls RJ, Woloszko J. Effects of short term sacral nerve stimulation on anal and rectal function in patients with anal incontinence. Gut. 1999;44:407-12.

29. Rosen RC, Cappelleri JC, Smith MD, Lipsky J, Pena BM. Development and evaluation of an abridged, 5-item version of the International Index of Erectile Function (IIEF-5) as a diagnostic tool for erectile dysfunction. Int J Impotence Res. 1999;11:319.

30. Jenkinson C, Coulter A, Wright L. Short form 36 (SF36) health survey questionnaire: normative data for adults of working age. BMJ. 1993;306:1437-40.

31. O'Gorman C, Stack J, O'Ceilleachair A, Denieffe S, Gooney M, McKnight M, et al. Colorectal cancer survivors: an investigation of symptom burden and influencing factors. BMC Cancer. 2018;18. https://doi.org/10.1186/s12885-0184923-3.
32. Brooks R, Group E. EuroQol: the current state of play. Health policy. 1996;37: 53-72.

33. Rullier E, Zerbib F, Marrel A, Amouretti M, Lehur P-A. Validation of the French version of the fecal incontinence quality-of-life (FIQL) scale. Gastroenterol Clin Biol. 2004;28:562-8.

34. Von Elm E, Altman DG, Egger M, Pocock SJ, Gøtzsche PC, Vandenbroucke JP. The strengthening the reporting of observational studies in epidemiology (STROBE) statement: guidelines for reporting observational studies. Ann Intern Med. 2007;147:573-7.

35. Mirnezami A, Mirnezami R, Chandrakumaran K, Sasapu K, Sagar P, Finan P. Increased local recurrence and reduced survival from colorectal cancer following anastomotic leak: systematic review and meta-analysis. Ann Surg. 2011;253:890-9.

36. den Dulk M, Marijnen CAM, Collette L, Putter H, Påhlman L, Folkesson J, et al. Multicentre analysis of oncological and survival outcomes following anastomotic leakage after rectal cancer surgery. Br J Surg. 2009;96:1066-75.

37. McDermott FD, Heeney A, Kelly ME, Steele RJ, Carlson GL, Winter DC. Systematic review of preoperative, intraoperative and postoperative risk factors for colorectal anastomotic leaks. Br J Surg. 2015;102:462-79.

38. Matthiessen $P$, Hallböök $O$, Andersson M, Rutegård J, Sjödahl R. Risk factors for anastomotic leakage after anterior resection of the rectum. Color Dis. 2004;6:462-9.

39. Rullier E, Laurent C, Garrelon JL, Michel P, Saric J, Parneix M. Risk factors for anastomotic leakage after resection of rectal cancer. Br J Surg. 1998;85:355-8.

40. Lim M, Akhtar S, Sasapu K, Harris K, Burke D, Sagar P, et al. Clinical and subclinical leaks after low colorectal anastomosis: a clinical and radiologic study. Dis Colon Rectum. 2006:49:1611-9.

41. Breukink SO, van der Zaag-Loonen HJ, Bouma EMC, Pierie JPEN, Hoff C, Wiggers T, et al. Prospective evaluation of quality of life and sexual functioning after laparoscopic total mesorectal excision. Dis Colon Rectum. 2007;50:147-55.

42. Bloemen JG, Visschers RGJ, Truin W, Beets GL, Konsten JLM. Long-term quality of life in patients with rectal cancer: association with severe postoperative complications and presence of a stoma. Dis Colon Rectum. 2009;52:1251-8.

43. Hoerske C, Weber K, Goehl J, Hohenberger W, Merkel S. Long-term outcomes and quality of life after rectal carcinoma surgery. Br J Surg. 2010; 97:1295-303.

44. Ashburn JH, Stocchi L, Kiran RP, Dietz DW, Remzi FH. Consequences of anastomotic leak after restorative proctectomy for cancer: effect on longterm function and quality of life. Dis Colon Rectum. 2013;56:275-80.

45. Nesbakken A, Nygaard K, Lunde OC. Outcome and late functional results after anastomotic leakage following mesorectal excision for rectal cancer. $\mathrm{Br}$ J Surg. 2001;88:400-4.

\section{Publisher's Note}

Springer Nature remains neutral with regard to jurisdictional claims in published maps and institutional affiliations.

\section{Ready to submit your research? Choose BMC and benefit from:}

- fast, convenient online submission

- thorough peer review by experienced researchers in your field

- rapid publication on acceptance

- support for research data, including large and complex data types

- gold Open Access which fosters wider collaboration and increased citations

- maximum visibility for your research: over $100 \mathrm{M}$ website views per year

At BMC, research is always in progress.

Learn more biomedcentral.com/submissions 